\title{
Redes sociais como ferramenta de visibilidade das mulheres nas ciências exatas: análise do perfil @lindasdaengenharia
}

\author{
Sara das Mercês Silva ${ }^{1}$, Geisiane S. Matos ${ }^{1}$, Tatiane A. Nascimento ${ }^{2}$, \\ Fabíola Pantoja O. Araújo ${ }^{1}$ \\ ${ }^{1}$ Instituto de Ciências Exatas e Naturais (ICEN) - Universidade Federal do Pará (UFPA) \\ Telefone 3201-7405 - 66075-110 - Belém - PA - Brasil \\ ${ }^{2}$ Faculdade de Computação - Campus Castanhal - Universidade Federal do Pará (UFPA) \\ Av. dos Universitarios - 68746-360 - Castanhal- PA - Brasil \\ maru.merces18, geisi.mattos.s, ttatyalves\{@gmail.com\}, fpoliveira@ufpa.br
}

\begin{abstract}
This research aims to verify the visibility of women who work in the exact sciences, through social media, analyzing the profile @lindasdaengenharia that discloses professional information about women in the exact sciences. The results obtained through the analysis of the metrics showed that the profile has a reach of 88 thousand users per month.
\end{abstract}

\begin{abstract}
Resumo. Esta pesquisa verificar a visibilidade de mulheres que atuam nas ciências exatas, através das redes sociais, analisando o perfil @ lindasdaengenharia que divulga informações profissionais de mulheres das ciências exatas. Os resultados obtidos por meio da análise das métricas mostraram que o perfil tem um alcance de 88 mil usuários por mês.
\end{abstract}

\section{Introdução}

A redes sociais vêm influenciando as mais diferentes áreas da vida das pessoas. As mídias digitais se tornam cada vez mais presentes em atividades de lazer, aprendizado e frequentemente em atividades profissionais [Milson et al. 2020]. A participação e envolvimento das mulheres em áreas da ciência e tecnologias de informação têm se tornado centro de debates em diferentes espaços. Segundo Campos $e$ de Melo (2020) é perceptível nas salas de aulas dos cursos de exatas e ciências a diferença entre o quantitativo de meninos e meninas, principalmente em périodos próximos ao término do curso.

As mídias digitais têm recebido um crescimento potencial de usuários femininos. Essa ocupação de mulheres é marcada pela discussão de temáticas importantes que vêm sendo levantadas como pauta no meio social, sendo este ambiente um propulsor de fácil promoção e propagação de diferestes discursos [Pedrosa and Zanello 2016]. O presente estudo quer enxergar o incentivo à visibilidade de mulheres na Ciência, através das redes sociais. Este artigo está estruturado da seguinte maneira: na Seção 2 é descrita a metodologia usada na pesquisa e apresentado o perfil @lindasdaengenharia, analisado durante o presente estudo. Na Seção 3 são expostos os resultados da análise das informações disponíveis no próprio Instagram. Por fim, na Seção 4 são apresentadas as considerações finais deste trabalho. 


\subsection{As midias sociais como espaço de comunicação}

No que se refere a imagem das mulheres em redes sociais, existem pesquisas que relatam resultados positivos como em Fernades (2019) que discute a hashtag DeixaElaTrabalhar, surgindo como um manifesto de jornalistas mulheres contra o assédio e preconceito enfrentados por elas no jornalismo esportivo. Os resultados das análises revelaram que a hashtag cumpriu sua função enquanto ciberativismo. Entre perfis que compartilham conteúdos sobre mulheres na Ciência e Engenharia destacam-se @meninasdigitaissbc ${ }^{1}$, @onumulheres $b r^{2}$. Os perfis citados usam o Instagram como ferramenta para engajar meninas e mulheres em diferentes áreas da Ciência, compartilhar e disseminar informações e histórias de mulheres, promovendo a visibilidade de mulheres que atuam nessas áreas e divulgando ações, que visam aproximar meninas e Ciência.

A respeito de perfis no Instagram voltados para Estudos e Ciência, em seu trabalho Costa (2019) relata a experiência do desenvolvimento de um perfil no Instagram em parceria com o Laboratório de Microscopia da Universidade Federal de Santa Catarina Campus Araranguá, na área biológica com o nome de usuário @atlasmicroscopia que tem por finalidade o compartilhamento de imagens realizadas no laboratório provenientes de aulas práticas dos cursos da área da saúde. Os autores afirmam que o perfil tem atingido o seu propósito de divulgar e compartilhar conteúdo científico e contribuindo na construção do conhecimento.

É importante destacar as inúmeras vantagens relacionadas às questões sociais que estão ligadas ao ambiente online. Assuntos relacionados à mulheres como política, economia, tecnologia e ciência têm se apresentado como pautas importantes em ambientes de discussão e autores como Pires and Castro (2020) citam o movimento de ciberativismo, que está ligado ao crescimento de movimentos sociais nas redes sociais, esse fenomeno é apresentado como estratégia para importantes assuntos e temas em debates, que estão sendo inseridos em ambientes virtuais de integração, utilizando da velocidade da internet para informar e conscientizar cada vez mais mulheres [Lemos et al. 2009]. É importante ressaltar que a falta de exemplos femininos conhecidos pelo público em geral é uma das causas do afastamento de mulheres de áreas como a Computação. Segundo Schwartz (2006), Sales et al. (2014) e Castro (2013), a escassez de profissionais mulheres conhecidas dentro da profissão e poucas informações sobre oportunidades de crescimento de carreira, são dois motivos que caracterizam o afastamento feminino destas áreas de atuação.

\section{Metodologia}

Na presente pesquisa o processo metodológico de análise das informações é quantitativo [Prodanov and Freitas 2013], pois utilizou as métricas, disponíveis no Instagram, para aferir os dados, focando em avaliar o alcance de público do perfil e consequentemente a visibilidade que gera às mulheres e informações veículadas no @ lindasdaengenharia. O perfil, idealizado por uma aluna de mestrado em Ciência da Computação, durante sua graduação em Engenharia de Computação, ambos na [UFPA, surgiu para engajar a própria idealizadora do perfil e outras alunas a continuarem em seus respectivos cursos, tanto na área de Computação quanto Engenharia, utilizando-se da mídia social e de redes sociais.

\footnotetext{
${ }^{1}$ https://www.instagram.com/meninasdigitaissbc/?hl=pt-br

${ }^{2} \mathrm{https} / / / \mathrm{www}$. instagram.com/onumulheresbr/?hl=pt-br
} 
O Instagram disponibiliza ao usuários informações para poder aferir o crescimento do perfil, seu alcance, o público que acessa os conteúdos e sua a localização, assim como as publicações que geram mais engajamento e interação com a audiência. Usando essas informações, será possível identificar o crescimento do perfil analisado, assim como seu público-alvo, o número de pessoas que acessam as informações compartilhadas no perfil, o crescimento do perfil no período observado, entre outras informações pertinentes.

\subsection{O perfil @lindasdaengenharia}

O perfil na rede social Instagram, intitulado @ lindasdaengenharia, surgiu em 2015 para compartilhar histórias de mulheres das áreas de Engenharia e Computação. O perfil se mantém ativo, com publicações frequentes, seu acesso é público e o conteúdo gerado pelo perfil é aberto. Compartilha e divulga histórias de mulheres que atuam nas áreas e eventos de Ciência e Tecnologia focados no público feminino. Hoje o perfil é seguido por mais de 30 mil pessoas, sendo mais de $70 \%$ do público feminino, na faixa etária de 18 a 34 anos de idadea. No período avaliado, o perfil manteve seu crescimento positivo, ou seja, ganhou mais seguidores (827 novos seguidores) do que perdeu (794 deixaram de seguir) e teve um crescimento $0,1 \%$ maior no período analisado (fevereiro a março de 2021), do que no período anterior (janeiro a fevereiro de 2021) (Figura 1).

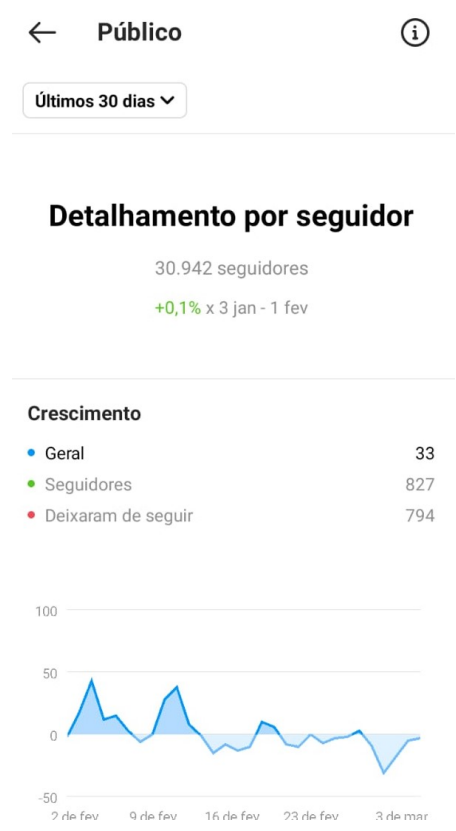

Figura 1. Número de seguidores do perfil

\section{Análise das informações de público disponíveis no Instagram}

A análise dos dados foi realizada da seguinte forma: através da investigação das informações presentes no Instagram que para avaliação de informações disponibiliza suas próprias métricas e permite essa visualização de informações através de recursos e ferramentas gratuitas para os usuários da rede social. Assim analisou-se os dados de público, atividades e alcance do perfil, para aferir a audiência das publicações e informações compartilhadas no perfil, aqui analisado. 
Os conteúdos compartilhados no perfil, são nos formatos de fotos mais textos (disponíveis no feed) e vídeos curtos (disponíveis nos stories reels e igtv). Os conteúdos contam exemplos e histórias de profissionais e estudantes de ciências exatas, eventos da área, pesquisas sobre a participação de mulheres na Engenharia e Computação, cursos gratuitos, informações acadêmicas (como por exemplo: escrita de artigos, pós-graduação, rotina de estudo, etc.). Também são realizadas enquetes sobre proposta de temas a serem abordados no perfil, permitindo assim uma interação direta do público-alvo com o conteúdo entregue. Espera-se que disseminar essas informações em redes sociais as tornem acessíveis a um público muito maior de pessoas, em especial mulheres.

O perfil, até o dia da escrita desse artigo, conta com mais de 30.500 seguidores, dos quais $70.9 \%$ são mulheres e $29.1 \%$ homens (Figura 2), deixando evidente que o conteúdo veículado (mulheres nas ciências exatas) no perfil é de grande interesse do público feminino. Redes sociais podem ser uma ferramenta para despertar o interesse de meninas por Computação e Ciência ao divulgar exemplos de profissionais mulheres da área,pois Beaubouef and Zhang (2011) apontam como principais fatores que levam ao desinteresse pela Computação, por parte das mulheres, são a falta de "modelos femininos" na área, a falta de incentivo para que sigam uma carreira na área e não sentirem-se a vontade com a cultura da Computação.

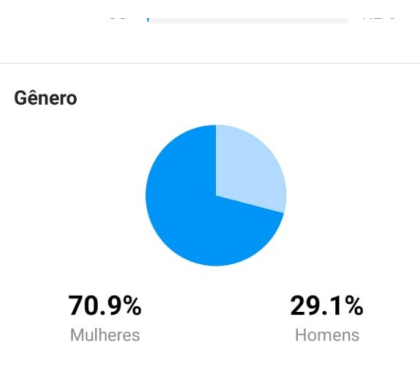

Figura 2. Gênero dos seguidores do perfil - (Gráfico disponível no Instagram)

No período analisado de 30 dias, o conteúdo pulicado no perfil alcançou quase 90 mil contas que tiveram acesso à informações sobre ciências exatas, exemplos de mulheres que atuam na área, eventos e informações sobre Computação e Engenharia. Mais de 18 mil pessoas interagiram com o conteúdo do perfil: seja curtindo, comentando ou compartilhando as publicações e informações em seus perfis pessoais, aumentando assim o alcance do @ lindasdaengenharia. A postagem com maior número de curtidas, mais de 2.000 likes, é a foto de formatura de uma engenheira negra e a foto com menos curtidas, cerca de 70 likes, é um texto explicativo sobre pós-graduação.

\section{Conclusão}

A falta de exemplos femininos na Computação e Engenharia, são fatores que podem comprometer o ingresso de mulheres na Ciência. Entretanto as mídias sociais, tão populares hoje, podem contribuir positivamente para a divulgação de informações e exemplos da atuação feminina na Ciência. É importante reafirmar constantemente o acesso de mulheres à informação para que assim possam identificar o quão importante é a sua posição na sociedade, seja no âmbito escolar de trabalho ou como cidadã, reafirmando seus direitos conquistados. Tendo em vista que um dos fatores, apontados como negativos para mulheres não optarem por Computação, é exatamente a falta de exemplos de profissionais e 
estudantes mulheres dentro da Computação. Compartilhar exemplos femininos, através das redes sociais, pode ser considerado uma forma de ajudar a promover a divulgação e visibilidade das mulheres na Ciência tornando essas informações alcançáveis a mais pessoas. O @lindasdaengenharia vai além das redes sociais, pois participa de palestras e entrevistas voltadas para o público feminino, engajando outras mulheres. Por fim, ressalta-se a importância deste diálogo com a audiência disponível e também reitera-se a importância dos trabalhos futuros, onde indica-se desenvolver atividades de caráter extensionistas, que envolvam redes sociais, palestras e oficinas sobre cursos e profissões nas áreas de Ciência, Tecnologia e Engenharia, voltados para mulheres estudantes do ensino básico e assim despertar, no público feminino, o interesse por Ciência, Computação e Engenharia.

\section{Referências}

Beaubouef, T. and Zhang, W. (2011). Where are the women computer science students? In Journal of Computing Sciences in Colleges.

Campos, G. M. and de Melo, A. C. M. (2020). Maria bonita nas ciências:: um projeto para divulgar ciências às meninas de escolas públicas. In Anais do XIV Women in Information Technology, pages 50-59. SBC.

Castro, B. (2013). Os gargalos para o ingresso e a permanência das mulheres no mercado de ti no brasil. In XII Conferencia Regional sobre la Mujer de la America Latina y Caribe.

Costa, F. V. (2019). Uso do instagram como ferramenta de estudo. Research, Society and Development, 8(10).

Fernandes, B. S. O. (2019). Mulheres jornalistas no meio esportivo televisivo: estudo de caso do movimento deixaelatrabalhar no instagram. https://repositorio. ufu.br/handle/123456789/28695.

Lemos, M. G. et al. (2009). Ciberfeminismo: Novos discursos do feminino em redes eletrônicas.

Milson, A. L. S., Ribeiro, I. M. C., Andrade, I. A., Gonçalves, J. M., Laboissiere, L. M., Ferreira, M. D., Dalip, D. H., Brandão, M. A., and Moro, M. M. (2020). Elas na ciência: Website com jogos para divulgar personalidades femininas. In Anais do XIV Women in Information Technology, pages 10-19. SBC.

Pedrosa, M. and Zanello, V. (2016). (in) visibilidade da violência contra as mulheres na saúde mental. Psicologia: Teoria e Pesquisa, 32(SPE).

Pires, D. and Castro, A. M. (2020). Todo espaço é político: Ativismo de mulheres nas redes sociais. Revista Docência e Cibercultura, 4(2):143-161.

Prodanov, C. C. and Freitas, E. C. (2013). Metodologia do trabalho científico: métodos e técnicas da pesquisa e do trabalho acadêmico- $2^{a}$ Edição. Editora Feevale.

Sales, A., Calado, B., Silva, D. R., Mattos, G., and Moreira, J. A. (2014). Dificuldades para o ingresso e permanência na ciência e engenharia da computação: um olhar feminino. $18^{\circ}$ REDOR, UFRPE. Recife, PE.

Schwartz, J. (2006). Mulheres na informática: quais foram as pioneiras? cadernos pagu, pages 255-278. 